\title{
Kajian Jasa Travel Rute Simpang Pematang-Bandar Lampung Ditinjau Dari Biaya Operasional Kendaraan Penumpang
}

\author{
Diana Nur Afni ${ }^{(1)^{*}}$, Sumiyati ${ }^{(2)}$ \\ ${ }^{(1)}$ Universitas Sang Bumi Ruwa Jurai, ${ }^{(2)}$ Universitas Sang Bumi Ruwa Jurai \\ email korespondensi: diana.nurafni@gmail.com ${ }^{1 *}$
}

\begin{abstract}
Abstrak.
Seiring dengan meningkatnya pertumbuhan penduduk maka kebutuhan akan sarana dan prasarana penunjang kegiatan masyarakat meningkat pula termasuk sarana dan prasarana transporatasi. Kecamatan Simpang Pematang merupakan kecamatan yang terletak di lokasi yang cukup strategis di Kabupaten Mesuji di mana Kecamatan Simpang Pematang terletak berbatasan dengan Kabupaten Tulang Bawang Barat dan mesuji memiliki akses pintu tol. Hal tersebut menjadikan Kecamatan Simpang Pematang pusat keluar masuknya penumpang transportasi jalur darat. Sehingga hal tersebut berpengaruh pada meningkatnya kebutuhan akan sarana angkutan umum untuk mendukung mobilitas masyarakat di Kecamatan Simpang Pematang. Tujuan penelitian ini adalah untuk menganalisis biaya operasional yang mesti dikeluarkan oleh pemberi jasa travel rute Simpang Pematang-Bandar Lampung. Penelitian ini menggunakan penelitian kuantitatif dengan yang dijadikan sampel pada penelitian ini adalah jasa travel yang menggunakan mobil Inova atau Avanza. Lokasi penelitian dilaksanakan pada Paguyuban Travel Kabupaten Mesuji. Hasil penelitian didapat bahwa Biaya operasional kendaraan travel perkendaraan-km/tahun yang melewati tol lebih rendah dari pada yang tidak melalui tol.
\end{abstract}

Kata Kunci: Biaya Operasional Kendaraan. Jasa Travel, Kendaraan Penumpang,

\begin{abstract}
.
Along with increasing population growth, the need for facilities and infrastructure to support community activities also increases, including transportation facilities and infrastructure. Simpang Pematang sub-district is a sub-district which is located in a strategic location in Mesuji Regency, where Simpang Pematang sub-district is bordered by Tulang Bawang Barat Regency and Mesuji has access to toll gates. This makes Simpang Pematang District the center of entry and exit for land transportation passengers. So that this affects the increasing need for public transportation facilities to support community mobility in Simpang Pematang District. The purpose of this study was to analyze the operational costs that must be incurred by travel service providers for the Simpang Pematang-Bandar Lampung route. This study uses quantitative research with which the sample in this study is travel services that use Inova or Avanza cars. The location of the research was carried out at the Travel Association of Mesuji Regency. The results showed that the operational costs of travel vehicles that pass through the toll road are lower than those that do not go through the toll road.
\end{abstract}

Keywords: Vehicle Operating Costs. Travel Services, Passenger Vehicles,

\section{PENDAHULUAN}

Transportasi merupakan layanan angkutan penumpang yang tersedia dan dapat digunakan oleh masyarakat umum. Transportasi biasanya dikelola menggunakan jadwal operasional, rute yang ditetapkan dan biaya tiap perjalannanya. Peran transportasi erat kaitannya dengan pertumbuhan suatu daerah dimana transportasi merupakan fasilitas penunjang, pendorong dan penggerak kegiatan masyarakat berupa kegiatan sosial, ekonomi, pendidikan, keagamaannya dan sebagainya. Oleh karena itu, dibutuhkan suatu fasilitas transportasi yang cepat, aman, nyaman dan terjangkau bagi masyarakat. Salah satu moda transportasi umum tersebut diantaranya yaitu travel. Komunikasi serial ini sangatlah populer dan kebanyakan didunia industri.

Terbatasnya sarana angkutan umum yang tersedia di Kecamatan Simpang Pematang seperti mikrolet, bus, ojek dan angkutan darat 
sejenisnya maka masyarakat memilih menggunakan sarana angkutan umum lainnya yaitu jasa travel yang memiliki armada lebih banyak dan dapat menjangkau wilayah tujuan lebih luas sehingga dinilai dapat memenuhi kebutuhan masyarakat akan sarana atau moda transportasi darat.

Selain hal tesebut, moda transportasi jasa travel dipilih oleh masyarakat karena memiliki keunggulan yaitu fleksibilitasnya melayani penumpang. Jasa travel dapat diminta menjemput di tempat penumpanng berangkat kemudian diantar hingga ke tempat tujuannya tepat di depan pintu.

Tersedianya alternatif untuk moda transportasi yaitu layanan travel dengan rute Simpang Pematang - Bandar Lampung membantu masyrakat khususnya masyarakat Simpang Pematang untuk memenuhi kebutuhan akan sarana transportasi darat. Mobilitas masyarakat ke Kota Bandar Lampung dinilai tinggi dilihat dari minat masyarakat akan rute tersebut dikarenakan Bandar Lampung merupakan kota terbesar di Provinsi Lampung di mana merupakan pusat ekonomi dan pendidikan. Oleh karena itu, dalam penelitian ini akan mengkaji Biaya Operasional Kendaraan (BOK) jasa travel rute Simpang Pematang Mesuji dan mengkaji tarif penumpangnnya.

Metode PCI merupakan metode empiris untuk menghitung biaya operasional kendaraan yang dikembangkan oleh Pacific Consultant International (PCI). Model PCI ini menyatakan bahwa Biaya Operasi Kendaraan (BOK) adalah penjumlahan dari biaya gerak (running cost) dan biaya tetap (standing cost). Perhitungan Biaya Operasi Kendaraan (BOK) dengan metode ini merupakan fungsi dari kecepatan dan dibedakan untuk BOK jalan tol dan BOK non tol. Perhitungan komponen BOK menggunakan Metode PCI menggunalan satuan per $1000 \mathrm{~km}$ sehingga untuk mendapatkan nilai satuan per $\mathrm{km}$ diperlukan jarak dari yang dilalui dengan kecepatan (running speed) dalam km/jam.

Persamaan untuk menghitung Biaya Operasional Kendaraan (BOK) pada metode ini dapat dilihat sebagai berikut:

$$
B O K=B T T+B T
$$

Keterangan:

$B O K=$ Biaya Operasional Kendaraan

$B T T=$ Biaya Tidak Tetap (Variable Cost atau Running Cost)

BT = Biaya Tetap (Standing Cost atau Fixed Cost)

Biaya tetap (standing cost atau fixed cost) merupakan biaya yang terdiri dari penjumlahan komponen-komponen pembiayaan yang terdiri dari biaya penyusutan, biaya awak kendaraan, biaya bunga modal dam biaya asuransi. Biaya tetap dapat dihitung dengan persamaan sebagai berikut:

$$
B T=B p i+B+B M o+B A
$$

Keterangan :

$B T$ = Biaya Tetap (Standing Cost atau Fixed Cost) (Rp/km)

$B p i \quad=$ Biaya Depresiasi $(\mathrm{Rp} / \mathrm{km})$

$B=$ Biaya Awak Kendaraan $(\mathrm{Rp} / \mathrm{km})$

$B M o=$ Biaya Modal $(\mathrm{Rp} / \mathrm{km})$

$B A=$ Biaya Asuransi $(\mathrm{Rp} / \mathrm{km})$

Biaya tidak tetap (Variable Cost atau Running Cost) adalah penjumlahan dari komponen-komponen biaya yang terdiri dari konsumsi kendaraan yaitu bahan bakar minyak, biaya oli mesin, konsumsi suku cadang, biaya upah karyawan dan biaya ban. Biaya tidak tetap dapat dihitung dengan persamaan sebagai berikut :

$$
\begin{gathered}
B T T=B i B B M j+B O i+B p i+B u i \\
+B B i
\end{gathered}
$$

Keterangan :

BTT = Biaya Tidak Tetap (Variable Cost atau Running Cost) (Rp/km) 


$$
\begin{array}{rlrl}
\text { BiBBMj }= & \begin{array}{l}
\text { Biaya Konsumsi Bahan Bakar } \\
\text { Minyak }(\mathrm{Rp} / \mathrm{km})
\end{array} & B B i \quad=\text { Biaya Konsumsi Ban }(\mathrm{Rp} / \mathrm{km}) \\
B p i & \text { Biaya Pemeliharaan }(\mathrm{Rp} / \mathrm{km}) & & \begin{array}{c}
\text { Persamaan untuk menghitung komponen- } \\
B O i
\end{array}= \\
B u i & \text { Biaya Konsumsi Oli }(\mathrm{Rp} / \mathrm{km}) & \text { kiaya Upah Tenaga Pemeliharaan } & \text { kompon nilai BOK dalam metode PCI pada } \\
& (\mathrm{Rp} / \mathrm{km}) & & \begin{array}{l}
\text { kendaraan golongan I (mobil) dapat dilihat } \\
\text { pada tabel Persamaan Perhitungan: }
\end{array}
\end{array}
$$

Tabel 1. Persamaan Perhitungan BOK

\begin{tabular}{clll}
\hline No & \multicolumn{1}{c}{$\begin{array}{c}\text { Komponen } \\
\text { Konsumsi }\end{array}$} & \multicolumn{1}{c}{ Jalan Tol } & \multicolumn{1}{c}{ Jalan Non Tol } \\
\hline 1. & BBM & $0,04376 \mathrm{~S}^{2}-4,94078 \mathrm{~S}+207,0484$ & $0,05693 \mathrm{~S}^{2}-6,42593 \mathrm{~S}+269,18567$ \\
2. & Oli Mesin & $0,00029 \mathrm{~S}^{2}-0,03134 \mathrm{~S}+1,69613$ & $0,00037 \mathrm{~S}^{2}-0,04070 \mathrm{~S}+2,20405$ \\
3. & Ban & $0,0008848 \mathrm{~S}-0,0045333$ & $0,0008848 \mathrm{~S}-0,0045333$ \\
4. & Pemeliharaan & $0,0000064 \mathrm{~S}+0,0005567$ & $0,0000064 \mathrm{~S}+0,0005567$ \\
5. & Mekanik & $0,00362 \mathrm{~S}+0,36267$ & $0,00362 \mathrm{~S}+0,36267$ \\
6. & Depresiasi & $1 /(2,5 \mathrm{~S}+100)$ & $1 /(2,5 \mathrm{~S}+100)$ \\
7. & Suku Bunga & $150 /(500 \mathrm{xS})$ & $150 /(500 \mathrm{xS})$ \\
8. & Asuransi & $38 /(500 \mathrm{xS})$ & $38 /(500 \mathrm{xS})$ \\
\hline
\end{tabular}

Analisis tarif adalah jumlah komponen biaya tetap (fixed cost), biaya tidak tetap (variable cost) dan biaya overhead dalam satuan per penumpang sehingga akan diperoleh hasil dari total biaya perpenumpang. Oleh karena itu, dapat diketahui apakah lebih tinggi atau lebih.

Fare Box Ratio (FBR) adalah perbandingan anatara nilai BOK pertahun dengan pendapatan pertahun. Nilai Fare Box Ratio (FBR) dapat memperlihatkan apakah jasa travel memperoleh untung atau rugi. Jika nilai Fare Box Ratio (FBR) > 1 maka jasa travel untung namun apabila FBR $<1$ maka jasa travel rugi.

\section{METODE PELAKSANAAN}

Jenis angkutan umum travel yang dijadikan sampel pada penelitian ini adalah mobil Inova atau Avanza. Berdasarkan jenis datanya, sumber data terbagi menjadi dua yaitu data primer dan data sekunder. Pada penelitian ini, yang termasuk data primer adalah data Biaya Operasional Kendaraan.

Data primer pada penelitian ini adalah Jumlah pendapatan, Jumlah penumpang, Harga Ban, Harga Suku Cadang, dan Harga Oli.
Selain itu, juga termasuk biaya yang dikeluarkan untuk pengoperasian secara tak langsung, seperti Gaji karyawan, Biaya perpanjangan STNK dan KIR Kendaraan, Biaya lain-lain seperti telepon. Data sekunder pada penelitian ini adalah data-data yang diperoleh dari instansi-instansi yang berkaitan dengan penelitian ini baik secara langsung maupun tak langsung serta data-data lainnya yang bersumber dari studi literatur. Lokasi penelitian dilaksanakan pada Paguyuban Travel Kabupaten Mesuji yang beralamat di Jl. Jendral Sudirman Desa Simpang Pematang, Kecamatan Simpang Pematang, Kab. Mesuji, Kode Pos (34698).

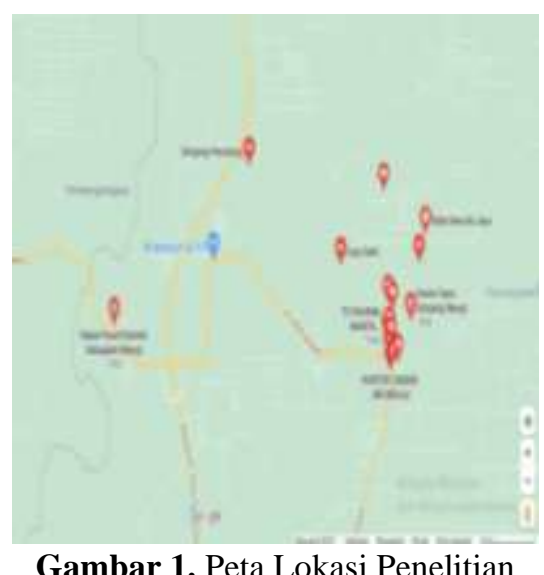

Gambar 1. Peta Lokasi Penelitian 
Data yang sudah diperoleh dari hasil wawancara dan dokumentasi. Selanjutnya data ini dianalisis dengan persamaan yang bersumber dari hasil studi literatur. Metode perhitungan biaya operasional kendaraan (BOK) yang digunakan pada penelitian ini adalah metode PCI.

Komponen biaya operasional kendaraan yang dihitung terdiri dari fixed cost (biaya langsung), variable cost (biaya tidak tetap dan biaya overhead. Analisis ini dapat dihitung dengan rumus :

$$
\begin{gathered}
B O K=B T+B T T \\
\text { Biaya Overhead }=\sum B O K \times 15 \% \\
\sum B O K=B O K+\text { Biaya Overhead }
\end{gathered}
$$

rendah dari tarif yang telah ditentukan (peraturan). Analisis ini dapat dihitung dengan rumus :

1. Tarif Pokok Penumpang

$$
=\frac{B O K}{\text { Kapasitas Penumpang pnp/tahun }}
$$

Tabel 2. Perhitungan Kecepatan (km/jam)

\begin{tabular}{cccc}
\hline Jenis Jalan & Jarak $(\mathbf{m})$ & Waktu Tempuh & Kecepatan \\
\hline Non Jalan Tol & 193.000 & $5 \mathrm{jam}$ & $38,6 \mathrm{~km} / \mathrm{jam}$ \\
Jalan Tol & 181.000 & $3 \mathrm{jam}$ & $60,3 \mathrm{~km} / \mathrm{jam}$ \\
\hline
\end{tabular}

Mobil travel yang melewati jalan tol adalah mobil kendaraan 1 . Kendaraan tersebut bermerek Toyota Avanza dengan model Minibus yang dibuat dan dirakit pada tahun 2010. Kendaraan tersebut berkapasitas isi silinder sebesar $1498 \mathrm{CC}$ dengan bahan bakar berupa bensin. diketahui bahwa nilai BOK perkendaraan-km/tahun travel yang melalui tol lebih kecil daripada yang melewati jalan tanpa tol. Nilai BOK perkendaraan-km/tahun travel yang melalui tol adalah sebesar Rp. 204.310.874,160 dan yang melewati jalan tanpa tol adalah Rp. 209.182.884,329. Dari perhitungan BOK perkilometer tersebut di atas dapat diketahui pula BOK kendaraan perkilometer tiap satu bulan. BOK Travel yang melalui tol perkilometer tiap satu bulannya adalah sebesar Rp. 17.025.906,180, sedangkan
2. Tarif Dasar Simpang Pematang-Bandar Lampung

$=$ Tarif Pokok Penumpang

+ (10\% dari Tarif Pokok Penumpang)

Nilai Fare Box Ratio (FBR) dapat diketahui menggunakan rumus:

$$
=\frac{\text { Pendapatan } / \text { tahun }}{\text { BOK } / \text { tahun }}
$$

\section{HASIL DAN PEMBAHASAN}

Dari hasil wawancara dan perhitungan menggunakan GPS, diperoleh data jarak tempuh dan waktu tempuh angkutan travel rute Simpang Pematang-Bandar Lampung yaitu dengan jarak 193.000m dengan waktu tempuh 5 jam apabila melalui jalan non-tol dan jarak 181.000 dengan waktu tempuh 3 jam apabila melalui jalan tol. yang tidak melalui tol adalah sebesar Rp. 17.431.907,027.

Menurut Suryaningsih dalam Kudadiri (2020), biaya operasional kendaraan akan meningkat apabila kecepatan perjalanan kendaraan rendah begitu pula sebaliknya. Pada penelitian ini, kecepatan kendaraan travel yang melewati tol lebih tinggi daripada kendaraan travel yang tidak melewati tol sehingga nilai biaya operasional kendaraan travel yang melalui tol lebih rendah. Menurut Suryaningsih dalam Kudadiri (2020), faktor-faktor yang mempengaruhi kecepatan rata-rata kendaraan adalah Besar volume lalu lintas, Kondisi geometri dan fisik jalan, Komposisi kendaraan berat di jalan yang dilalui, dan Aktivitas pada lahan sepanjang koridor jalan.

Selain itu, kecepatan lalu lintas dalan ruas jalan juga bervariasi yang disebabkan oleh 
faktor kondisi kendaraan dan faktor pengemudi kendaraan yang melintasi ruas jalan tersebut.

\section{KESIMPULAN DAN SARAN}

Berdasarkan analisis yang telah dilakukan pada penelitian tersebut dapat disimpulkan beberapa hal yaitu Biaya operasional kendaraan pada jasa travel rute Simpang Pematang-Bandar Lampung yang melewati jalan tol perkendaraan-kilometer adalah sebesar Rp. 204.310.874,160/tahun, Sedangkan jasa travel rute tersebut yang tidak melalui tol adalah sebesar Rp. 209.182.884,329/tahun. Sedangkan jika dihitung perbulan, maka BOK Travel yang melalui tol perkilometer tiap satu bulannya adalah sebesar Rp. 17.025.906,180 sedangkan yang tidak melalui tol adalah sebesar Rp. 17.431.907,027. Pendapatan yang diperoleh dari travel rute Simpang Pematang-Bandar Lampung melalui jalan tol adalah sebesar Rp. 340.200.000/tahun dan yang tidak melalui tol adalah sebesar Rp. 302.400.000/tahun.

Tarif yang dikenakan kepada penumpang saat ini adalah sebesar Rp.120.000/penumpang untuk jasa travel rute Simpang PematangBandar Lampung tanpa melalui tol sedangkan yang melalui tol adalah sebesar Rp. 135.000,00. Nilai FBR pada travel rute Simpang Pematang-Bandar Lampung yang melewati tol adalah 1,665 sedangkan yang tidak melewati tol adalah sebesar 1,446. Sehingga dapat disimpulkan bahwa jasa travel rute Simpang Pematang-Bandar Lampung yang melewati tol dan tanpa melewati tol memperoleh keuntungan.

Biaya operasional kendaraan travel perkendaraan-km/tahun yang melewati tol lebih rendah dari pada yang tidak melalui tol yaitu selisih sebesar Rp.4.872.010,169/tahun. Berdasarkan analisis hasil penelitian, hal tersebut dapat disebabkan oleh kecepatan kendaraan yang tidak melalui tol lebih rendah, jarak yang lebih panjang dan waktu tempuh yang lebih lama dari kendaraan travel yang melalui tol.

\section{DAFTAR PUSTAKA}

Abadi, Khoirul, "Kajian Biaya Operasional Kendaraan Angkutan Penumpang Umum Kota Malang". Media Teknik Sipil, Vol.10 No.1 (Februari, 2012).

Andriansyah, Manajemen Transportasi dalam Kajian dan Teori (Jakarta Pusat : Fakultas Ilmu Sosial dan Ilmu Politik Universitas Prof. Dr, Moestopo Beragama, 2015), hal 1-15.

Fatimah, Siti Pengantar Transportasi (Desa Pulung, Kecamatan Pulung, Kabupaten Ponorogo: Myria Publisher, 2019), hal 40-53

Hakim, Lukmanul, "Analisis Pengaruh Komponen Jalan Terhadap Capaian Laik Fungsi Jalan Tol (Studi Kasus : Jalan Tol Jakarta-Bogor-Ciawi)" Jurnal Teknik Sipil UBL, Vol. 8 No. 2 (Oktober 2017).

Keputusan Direktur Jenderal Perhubungan Darat Nomor : SK.687/AJ. 206/DRJD/ 2002 Tentang Pedoman Teknis Penyelenggraan Angkutan Penumpang Umum di Wilayah Perkotaan Dalam Trayek Tetap dan Teratur. Direktur Jenderal Perhubungan Darat. Jakarta. 